stomach alone or into the stomach and oesophagus. Evidence of regurgitation can often be found at endoscopy, and there may be obvious signs of mucosal irritation in the stomach or oesophagus. Biopsies of the mucosa may also confirm histological signs of gastritis or oesophagitis. Treatment with metoclopramide may minimise regurgitation and aid expulsion of the irritating regurgitated material back into the upper small intestine. Alternatively treatment may be given to bind the irritating bile salts with antacids or cholestyramine. Again revision surgery should be considered if troublesome symptoms persist without any signs of improvement over about two years. A Roux-en-Y reconstruction will divert the irritating bile and other fluids from the upper intestine well away from the stomach and give relief in between $70 \%$ and $80 \%$ of cases. ${ }^{4}$

The fourth vexed problem is diarrhoea, which is more likely after truncal vagotomy than one of the more selective procedures. As distinct from the diarrhoea that may accompany "dumping" symptoms diarrhoea occurring alone may be either an almost continuous daily occurrence or (just as distressing) in intermittent, often unpredictable episodes lasting from one to a few days at a time. Again, most patients' symptoms settle with the passage of time and one of the antidiarrhoeal agents usually gives satisfactory relief. Rarely the patient might be regarded as a candidate for the reversal of a $10 \mathrm{~cm}$ segment of jejunum located about $100 \mathrm{~cm}$ distal to the duodenojejunal flexure, so reducing the rate of transit through the small bowel. $^{3}$

Other miscellaneous sequelae which may be attributable to disordered physiology after vagotomy include true postprandial hypoglycaemia, the development of gall-bladder disease including stones, minor disorders of intestinal absorption, and even a hint of slightly increased risk of gastric cancer in later life. These are mentioned simply to be borne in mind but are not discussed in further detail.

Further surgical treatment for the various unwanted sequelae should be offered only very reluctantly: for many of the disorders, even when quite troublesome at first, can be expected to improve spontaneously even after many months, presumably as a result of adaptation within the upper gastrointestinal tract, and the overall satisfactory results from all types of secondary operation are in the region of only $60-80 \%$.

Recent moves towards more selective vagoiomy and in particular parietal-cell vagotomy (highly selective vagotomy) have reduced the incidence of most of the unwanted sequelae, apart from recurrent ulcer. With a few notable exceptions the overall incidence of recurrent ulcer after the newer forms of vagotomy from many centres throughout the world is between $15 \%$ and $20_{\%}$. Debate continues on whether it is better to have this higher recurrence rate in exchange for a reduction in all the other sequelae. We shall need to wait and see what the final recurrent ulcer rate will prove to be after this particular operation and, furthermore, how easy or difficult it will be to manage these recurrences successfully. Certainly the evidence from the treatment of recurrent ulcer after other procedures should give rise to caution. ${ }^{1}$

Unfortunately no way has been found of selecting the most appropriate operation for an individual patient with duodenal ulcer, despite much effort in this field. What is still needed is a procedure suitable for most patients that will give at the same time the highest insurance against further ulceration and the lowest legacy of other unwanted sequelae-and the search goes on. Meanwhile, patients who merit surgical treatment for duodenal ulcer should not feel unfairly dealt with by any of the popular vagotomy procedures: the close interest of so many surgeons means that they must be one of the most thoroughly followed up and assessed group of patients of all.

IAIN E Gillespie

Professor of Surgery,

University of Manchester,

Royal Infirmary,

Manchester M13 9WL

1 Stabile BE, Passaro E Jr. Recurrent peptic ulcer. Gastroenterology 1976; 70:124-35.

2 Alexander-Williams J. Gastric reconstructive surgery. Ann $R$ Coll Surg Engl 1973;52:1-17.

${ }^{3}$ Herrington JL, Sawyers JL. Remedial operations. In: Nyhus LM, Wastell C, eds. Surgery of the stomach and duodenum. 3rd ed. Boston: Little Brown and Co, 1977:537-69.

4 Kelly KA, Becker JM, Vanheerden JA. Reconstructive gastric surgery. Br f Surg 1981;68:687-91.

\section{A hundred and still going strong}

For over 30 years the Association of Clinical Pathologists has been publishing short technical manuals on laboratory medicine known as broadsheets. These describe specialist techniques for the guidance of all concerned in providing medical laboratory services and have covered topics in all disciplines of pathology ranging from the investigation of catecholamine-secreting tumours to the examination of a decomposed body. The broadsheets are published by the BMA with the assistance of the editorial staff of the fournal of Clinical Pathology and are commissioned by the ACP through its multidisciplinary committee on technical methods. They have been produced at the rate of around three a year, and number 100 has just been published (on the "Investigation of gonococcal infection"). ${ }^{1}$

As well as being circulated to the 2000 or so members of the ACP at home and abroad additional copies have been requested all over the world. Best selling topics have included the laboratory detection of abnormal haemoglobins, ${ }^{2}$ the investigation of blood transfusion reactions, ${ }^{3}$ the quantitative determination of porphyrins in urine, faeces, and erythrocytes, ${ }^{4}$ and photomicrography. ${ }^{5}$ At present three are in press, eight are well on in preparation, and as many again have been proposed. Several have been updated, particularly those dealing with rapidly changing laboratory methods such as the investigation of blood coagulation.

The Association of Clinical Pathologists believes that its broadsheets provide a useful service and raise the standards of laboratory medicine. With the increasing complexity and specialisation within the different disciplines of pathology it hopes that they will continue to do so well beyond the next 100 and into the foreseeable future.

J S LiLlEymaN

Publications Secretary,

Association of Clinical Pathologists,

London SW IW OLR

${ }^{1}$ Jephcott AE. Investigation of gonococcal infection. Association of Clinical Pathologists' Broadsheet. No 100. London: BMA, 1981.

2 Lehmann $\mathrm{H}$. The laboratory detection of abnormal haemoglobins. Association of Clinical Pathologists' Broadsheet. No 27. London: BMA, 1960.

${ }^{3}$ Tovey GH, Gillespie WA. The investigation of blood transfusion reactions. Association of Clinical Pathologists' Broadsheet. No 54. London: BMA, 1974. (Revised.)

1 Rimington C. Quantitative determination of porphobilinogen and porphyrins in urine and porphyrins in faeces and erythrocytes. Association of Clinical Pathologists' Broadsheet. No 70. London: BMA, 1971.

${ }^{5}$ Fawkes RS, Lendrum AC. Photomicrography. Association of Clinical Pathologists' Broadsheet. No 86. London: BMA, 1977. 